\title{
Organization and Application of ECLS Therapy- A Nationwide Survey in German Cardiosurgical Departments
}

\author{
Alexander Assmann ${ }^{1, *}$ Udo Boeken ${ }^{1, *}$ Stefan Klotz ${ }^{2}$ Wolfgang Harringer ${ }^{3}$ Andreas Beckmann ${ }^{4}$ \\ ${ }^{1}$ Department of Cardiovascular Surgery, Medical Faculty, Heinrich \\ Heine University, Duesseldorf, Germany \\ 2 Department of Cardiac and Thoracic Vascular Surgery, University \\ Address for correspondence Udo Boeken, MD, PhD, Department of \\ Cardiovascular Surgery, Medical Faculty, Heinrich Heine University, \\ Duesseldorf, Germany (e-mail: udo.boeken@med.uni-duesseldorf.de). \\ Hospital of Schleswig-Holstein, Lübeck, Germany \\ ${ }^{3}$ Clinic for Cardiac, Thoracic and Vascular Surgery, Klinikum \\ Braunschweig gGmbH, Braunschweig, Germany \\ ${ }^{4}$ German Society for Thoracic and Cardiovascular Surgery, Berlin, \\ Germany \\ Thorac Cardiovasc Surg 2019;67:164-169.
}

\author{
Abstract \\ Keywords \\ - cardiopulmonary \\ bypass \\ - extracorporeal life \\ support \\ - extracorporeal \\ membrane \\ oxygenation \\ - cardiac and \\ circulatory failure \\ - statistics \\ - survey
}

Background In context of the multidisciplinary German scientific guideline "Use of extracorporeal circulation (extracorporeal life support [ECLS]/extracorporeal membrane oxygenation) for cardiac and circulatory failure," a nationwide survey should depict the status of organization and application of ECLS therapy in Germany.

Methods Between June and October 2017, a standardized questionnaire consisting of 30 items related to ECLS therapy was sent to all German cardiosurgical departments, and all returned results were analyzed and evaluated.

Results The return rate amounted to $92.9 \%$ (78 out of 84 departments). In the participating departments, ECLS therapy is subject to different responsibilities, and exhibits divergent processes and various ways for specialization of the involved personnel. This also concerns local application standards, such as cannulation strategies, anticoagulation management, left ventricular unloading, antiwatershed treatment, and weaning from circulatory support.

Conclusion This nationwide survey underlines the necessity of a multidisciplinary guideline concerning ECLS therapy.

\section{Introduction}

Extracorporeal life support (ECLS) and extracorporeal membrane oxygenation (ECMO) have become important tools for the treatment of patients suffering from circulatory and pulmonary failure. Nowadays, miniaturization and simplification of device components for extracorporeal circulation enable fast and frequent application in the operation room, catheterization laboratory, or intensive care units. These

Both authors contributed equally to this study. devices can also be utilized to establish extracorporeal circuits in out-of-hospital scenarios and for safe transport of patients with circulatory or pulmonary failure. ${ }^{1,2}$ Most indications for extracorporeal circulation are patients with therapy-refractory cardiogenic shock, acute lung failure or embolism, and severe hypothermia. ${ }^{3-7}$ Concerning ECLS under resuscitation due to cardiac disease, there seems to be an improvement of patients' outcome regarding survival and neurological impairment. ${ }^{8,9}$ ECLS and ECMO particularly serve as a bridging therapy in emergency situations until further decisions or treatment options follow.

(c) 2019 Georg Thieme Verlag KG Stuttgart · New York
DOI https://doi.org/ 10.1055/s-0038-1675597. ISSN 0171-6425.

July 23, 2018

accepted

October 1, 2018

published online

November 20, 2018 
Although ECLS and ECMO are complex invasive therapies, their current organization and application are not based on general guidelines. In particular, the level of scientific evidence is low regarding indication, therapy initiation, and management, as well as institution-related aspects, such as main responsibility by different disciplines for separate tasks or the organization of intensive care units. In context of the multidisciplinary German guideline on "Use of extracorporeal circulation (ECLS/ECMO) for cardiac and circulatory failure," ${ }^{10}$ the present survey aimed to evaluate the current status of organization and application of ECLS therapy.

\section{Materials and Methods}

In June 2017, a standardized questionnaire consisting of 30 items was sent to all 84 German cardiosurgical departments for evaluation of the current status of organization and application of ECLS therapy.

While the first part of the questionnaire dealt with general information about the institution and the frequency of ECLS application, the second part focused on indications and contraindications, structural organization aspects, therapy management, weaning, and adverse events.

All returned questionnaires were anonymized at first before any analysis was performed. All data were collected utilizing categorical variables, for statistical comparisons of which two-sided Fisher's exact tests were applied. To analyze the occurrence of severe adverse events (SAE) in dependency on the ECLS center volume, for both variables (SAE and ECLS applications per year), the median value of the declared category range was assigned to each center, and the ratio SAE/ECLS value was calculated. Statistical comparison was conducted by means of a Mann-Whitney's $U$ test, as indicated by the Shapiro-Wilk's test for normality. Statistical significance was assumed if $p$-values were less than 0.05 . Data analysis was conducted with GraphPad Prism v5.04 (GraphPad Software, San Diego, United States).

\section{Results}

The return rate amounted to 78 out of 84 departments (92.9\%) in 79 institutions, whereof 76 departments (97.4\%) reported to implant ECLS devices. All percentages in the descriptive statistics are related to these 76 centers applying ECLS therapy. General characteristics are presented in -Table 1. The range of ECLS volume per center is depicted in -Fig. 1, while - Fig. 2 displays indications and contraindications for ECLS implantation.

\section{Program Structure and Responsibility}

Sixteen per cent of the departments applying ECLS reported that there is no commitment to obligatory responsibility in terms of ECLS initiation or further therapy management. Analysis of the responsibility for different ECLS-related tasks revealed that the cardiosurgical departments were involved in $98.7 \%$, whereas further therapy management and monitoring are multidisciplinary tasks in the majority of the institutions (-Table 2). However, application of ECLS is also
Table 1 General characteristics of the German cardiosurgical departments applying ECLS $(n=76)$

\begin{tabular}{|l|l|}
\hline Characteristics & Number $(\mathbf{n}, \%)$ \\
\hline University hospitals & $42(55.3 \%)$ \\
\hline$>1,000$ on-pump operations per year & $35(46.1 \%)$ \\
\hline Thoracic organ transplantation program & $23(30.3 \%)$ \\
\hline Assist device program & $64(84.2 \%)$ \\
\hline$>50$ ECLS therapies per year & $25(32.9 \%)$ \\
\hline Noncardiosurgical ECLS initiation & $47(62.7 \%)$ \\
\hline ECLS initiation outside of the center & $58(76.3 \%)$ \\
\hline$>10$ out-center ECLS per year & $13(17.1 \%)$ \\
\hline Out-center ECLS by external ECLS teams & $20(26.3 \%)$ \\
\hline
\end{tabular}

Abbreviation: ECLS, extracorporeal life support.

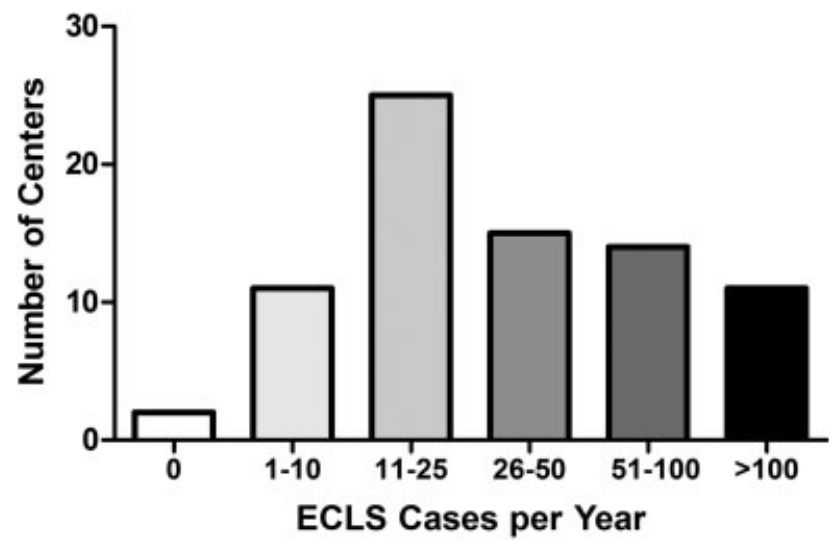

Fig. 1 ECLS volume of the 78 participating centers. ECLS, extracorporeal life support.

initiated without cardiosurgical expertise in $46.1 \%$, predominantly in cardiac catheterization laboratories or intensive care units. In $11.8 \%$ of the institutions, ECLS therapy is not continuously supported by clinical perfusionists. Alarmingly, in $10.7 \%$ of all centers, ECLS monitoring is performed by not specifically trained personnel. The organization of ECLS therapy was evaluated to be satisfactory (without need for substantial changes) by only $69.7 \%$ of the centers, whereas the percentage was significantly higher in departments with obligatory responsibilities of different disciplines for ECLS initiation and therapy management, as compared with those with variable responsibilities (-Fig. $\mathbf{3}$ ).

\section{Therapy Management and Monitoring}

Cannulation via the femoral arteries is applied in all institutions, while aortic or subclavian access is conducted in 89.5 or $67.1 \%$ of the departments. Central cannulation techniques are used by $40.5 \%$ in more than $25 \%$ of their patients. Pulsatile ECLS is applied in only $13.3 \%$ of the departments, and additional circulatory support by venting the left atrium or the left ventricle in $42.1 \%$, whereas most of these departments use it in less than $50 \%$ of their patients ( - Fig. 4A). To treat watershed phenomenon issues (Harlequin's syndrome) in ECLS patients 


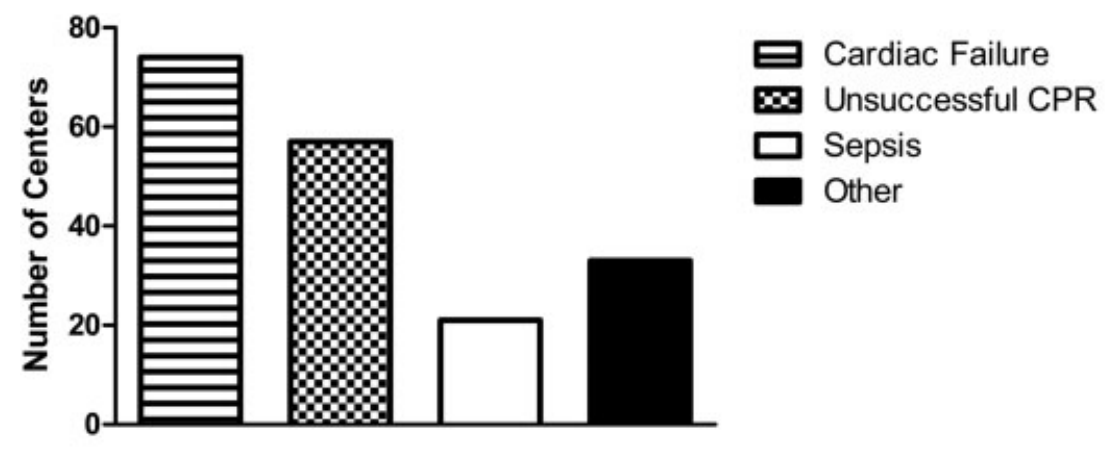

A

Indications

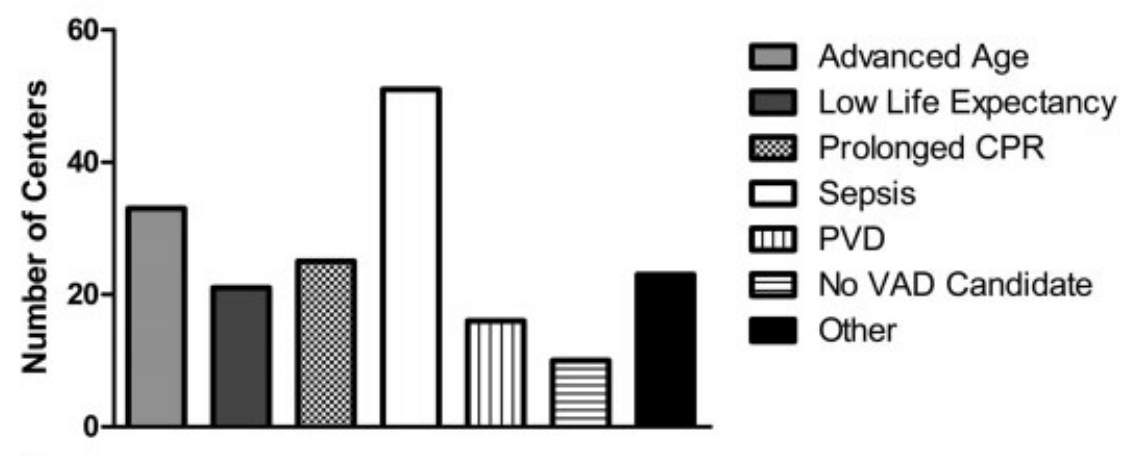

B Contraindications

Fig. 2 Indications and contraindications for ECLS therapy initiation. CPR, cardiopulmonary resuscitation; ECLS, extracorporeal life support; PVD, peripheral vessel disease; VAD, ventricular assist device.

Table 2 Responsibility of different disciplines in terms of cannulation and therapy monitoring

\begin{tabular}{|l|l|l|l|}
\hline & $\begin{array}{l}\text { Cardiac } \\
\text { surgery }\end{array}$ & Cardiology & Anesthesiology \\
\hline $\begin{array}{l}\text { ECLS } \\
\text { cannulation }\end{array}$ & $75(98.7 \%)$ & $36(47.4 \%)$ & $18(23.7 \%)$ \\
\hline $\begin{array}{l}\text { ECLS } \\
\text { monitoring }\end{array}$ & $75(98.7 \%)$ & $42(55.3 \%)$ & $45(59.2 \%)$ \\
\hline
\end{tabular}

Abbreviation: ECLS, extracorporeal life support.

Note: The number of centers $(n, \%)$ with involvement of the respective disciplines in the responsibility for ECLS cannulation and monitoring is displayed.

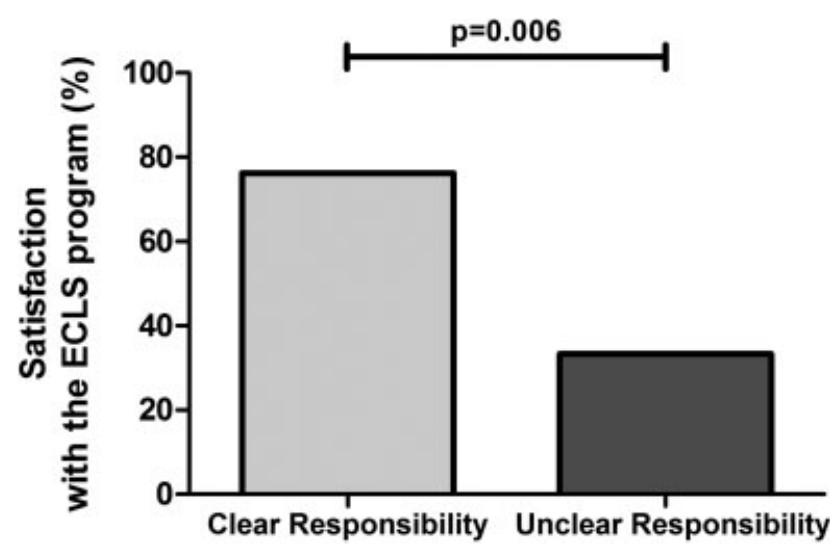

Fig. 3 Satisfaction with the local ECLS program in dependency on clearly defined responsibilities. ECLS, extracorporeal life support with preserved or recovered left ventricular ejection but severely impaired pulmonary gas exchange, aortic or subclavian cannulation is the favored option ( - Fig. 4B). Application of anticoagulants is monitored by means of activated clotting time (ACT) in $76.3 \%$ and partial thromboplastin time (PTT) in 73.7\%. Although the target values differ, the most common limits were found to be ACT $>150$ seconds and PTT $>50$ or $>60$ second ( - Fig. $\mathbf{5}$ ). ECLS therapy is partially conducted in spontaneously breathing and even in unsedated patients in $64.9 \%$ of the departments. The vast majority of departments (88.2\%) reported the occurrence of SAE under ECLS therapy, whereas centers with more than $50 \mathrm{ECLS}$ therapies per year had half the event rates as compared with centers with a caseload lower than 50 per year ( - Fig. 6). To assess parameters to decide on the weaning process, most centers rely on a combination of parameters such as echocardiography (97.4\%), clinical status (92.1\%), hemodynamic monitoring (88.2\%), and the course of catecholamine dosage (86.8\%).

\section{Discussion}

This report provides the results of the first nationwide survey on ECLS therapy in nearly all German cardiothoracic departments. Since ECLS has become a therapeutic option in various in- and out-of-hospital scenarios, it is an expanding field in cardiovascular medicine, so that evaluation and optimization of various aspects such as indication, application, organization, and patients' outcome are of broad interest. 


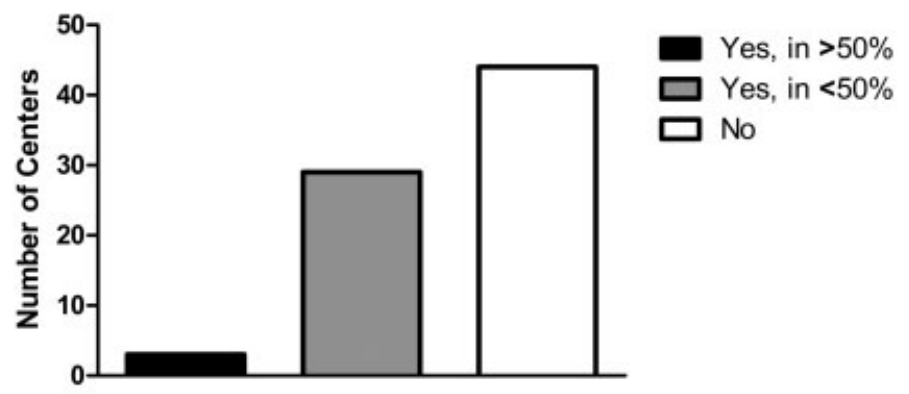

A LV Vent Implantation

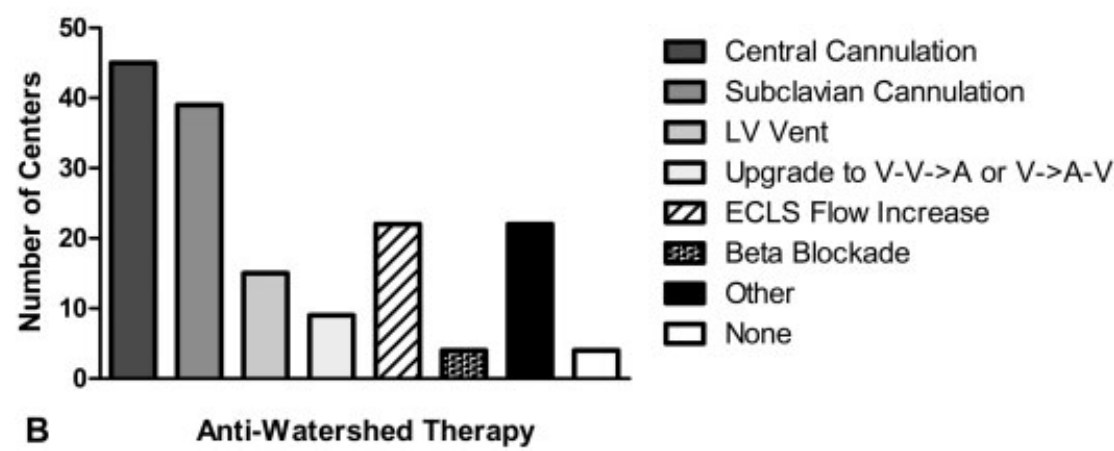

Fig. 4 Strategies to unload the LV and treat ECLS watershed phenomena (Harlequin's syndrome). ECLS, extracorporeal life support; LV, left ventricle; $\mathrm{V}-\mathrm{V} \rightarrow \mathrm{A}$, bicaval venous drainage and one arterial cannula; $\mathrm{V} \rightarrow \mathrm{A}-\mathrm{V}$, one venous cannula and arterial as well as central venous return cannulas.

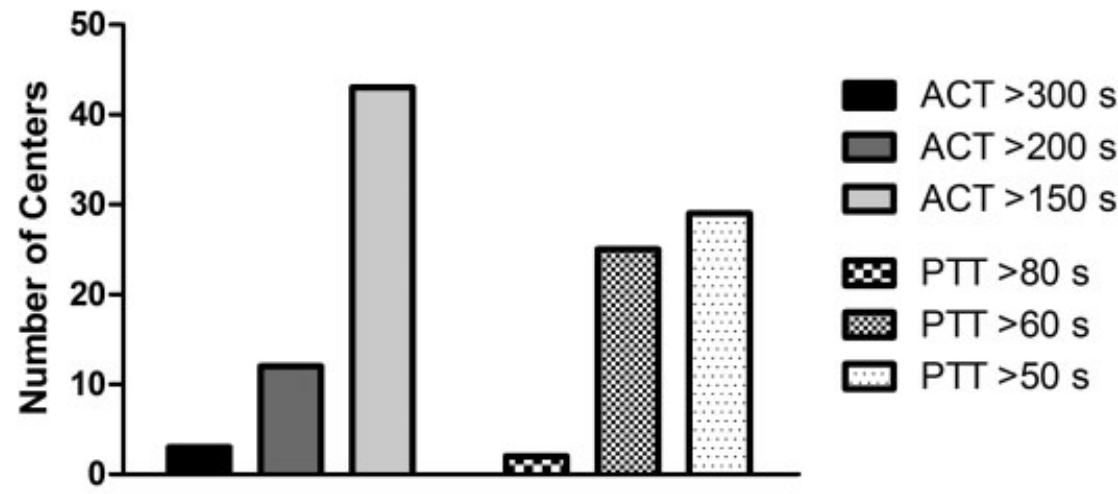

Anticoagulatory Target Value

Fig. 5 Target values for anticoagulatory therapy in ECLS patients. ACT, activated clotting time; ECLS, extracorporeal life support; PTT, partial thromboplastin time.

\section{Profile of the Participating Departments}

Almost every participating department reported the implantation of ECLS systems. However, the majority (67.1\%) implants less than one extracorporeal system per week on average. More than three out of four departments run emergency programs to initiate ECLS therapies outside of hospital and safely transfer the patients to their intensive care units. In many cases, these patients suffer from severe cardiogenic shock or cardiac arrest, and ECLS is applied shortly before or under ongoing cardiopulmonary resuscitation. If cardiac recovery is not expected and the clinical state of the patients justifies further treatment, assist device implantation or even heart transplantation may be considered. Due to the decreasing number of available donor organs in Germany, the heart and lung transplantation programs are focused on a few centers, while more than five out of six departments perform assist device implantations allowing for destination or bridge-to-transplant therapy. For patients with cardiogenic shock in in-hospital as well as out-ofhospital scenarios, and especially under resuscitation, ECLS support has the potential to improve neurological outcome and mortality, whereas particularly age, duration of resuscitation, and metabolic state have to be considered as potential contraindications. ${ }^{8,9,11-13}$

\section{Program Structure and Responsibility}

Reports on insufficient coordination, in particular regarding variable responsibility of different disciplines for ECLS 


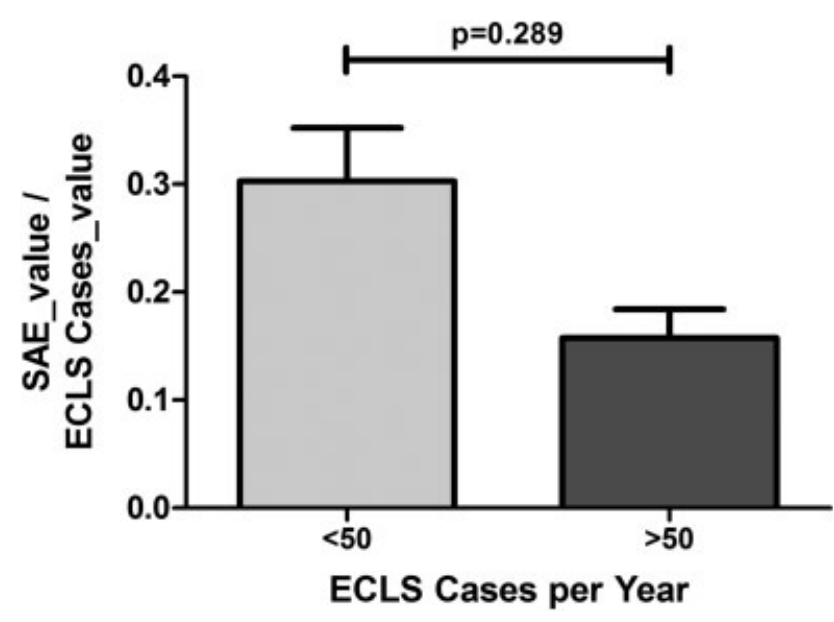

Fig. 6 Occurrence of SAE in dependency on the ECLS volume. ECLS, extracorporeal life support; SAE, severe adverse events.

therapy, underline the necessity to reconsider and improve the associated organizational and treatment processes. Furthermore, this survey points out that satisfaction of the applying physicians with the extracorporeal program is increased in centers with defined responsibilities. Close and constructive collaboration among cardiac surgeons, cardiologists, anesthesiologists, and clinical perfusionists is a crucial element for optimized treatment of severely diseased patients under ECLS therapy. ${ }^{14}$ In particular, early joint discussion and decision on critically ill patients and precise definition of the separate tasks are important. In this context, it is remarkable that in $46 \%$ of the participating departments, extracorporeal therapies are initiated without involving cardiac surgeons. Especially in emergency situations, the rate of serious complications, predominantly related to peripheral cannulation, is high. Establishing access to the peripheral vessels by skin incision or for central cannulation by immediate sternotomy is often the only remaining option. Therefore, institutions performing ECLS therapies should guarantee $24 \times 7 \times 365$ availability of qualified and experienced staff who are able to initiate all extracorporeal therapies by various access routes. This requirement has been previously postulated in a position paper on the routine use of ECLS systems. ${ }^{15}$ Furthermore, all personnel involved in the treatment of ECLS patients should be specially trained to adequately contribute to the therapy of these critically diseased, frequently multimorbid patients.

The present survey addressed only cardiosurgical departments. Besides these institutions, a growing number of cardiological departments and hospitals of primary care with low frequencies of extracorporeal therapy, both without a cardiosurgical department on site, are equipped with ECLS devices for emergency cases. Thus, it should be considered that the number of centers with potential for improvement of ECLS organization, safety, and patients' outcome may be actually substantially higher than this survey suggests.

\section{Therapy Management and Monitoring}

Initiation and application of ECLS therapy differ between the participating institutions. While most departments (89.5\%) apply central ECLS cannulation at least in selected patients, the strategies for left ventricular unloading and treatment of watershed phenomena are inconsistent. In terms of left ventricular unloading, central vent catheters as well as percutaneous ventricular assist devices improve the hemodynamics. ${ }^{16}$ In German cardiosurgical departments, a pulsatile flow concept for ECLS does not exist at considerable frequency. One of the most important aspects during extracorporeal circulation therapy is monitoring of the anticoagulatory treatment. The present survey shows that there is no nationwide standard for target values that are supposed to enable a safe anticoagulation status. This finding is in line with the results from a recent metaanalysis that could not declare evidence for recommendations on anticoagulation strategies or target values. ${ }^{17}$ In the present survey, SAE, such as unintentional decannulation, device thrombosis, pump failure, lower limb ischemia, or liver failure, were less frequent in centers with more than 50 ECLS therapies per year, whereas no statistically significant difference could be found. With regard to the weaning process, different techniques to assess the weaning potential, such as echocardiography, clinical status, hemodynamic monitoring, or the course of catecholamine dosage, are used by the majority of the centers. However, more evidence-based criteria are requested for optimization of the complex weaning process in ECLS patients.

\section{Conclusion}

According to the results of this survey, there is substantial room for further improvement concerning various aspects in the context of ECLS therapy in Germany. Moreover, current installation and actual management of extracorporeal therapies are heterogeneously conducted. Since ECLS patients suffer from severely compromised organ functions, and therefore need a continuous and at each time appropriate quality level of treatment, an evidence-based guideline is required. To address this need, an interdisciplinary German S3 guideline "Use of extracorporeal circulation (ECLS/ECMO) for cardiac and circulatory failure" is currently in preparation.

Note

This survey was conducted by the Working Group for Extracorporeal Circulation and Mechanical Circulatory Support and the board of directors of the German Society for Thoracic and Cardiovascular Surgery.

\section{Acknowledgments}

The authors did not receive funding for this project. Since both authors (A.A. and U.B.) provided major contributions to all aspects of this project, equal authorships were assigned in agreement with all co-authors.

\section{References}

1 Gariboldi V, Grisoli D, Tarmiz A, et al. Mobile extracorporeal membrane oxygenation unit expands cardiac assist surgical programs. Ann Thorac Surg 2010;90(05):1548-1552 
2 Javidfar J, Brodie D, Takayama H, et al. Safe transport of critically ill adult patients on extracorporeal membrane oxygenation support to a regional extracorporeal membrane oxygenation center. ASAIO J 2011;57(05):421-425

3 Ko WJ, Lin CY, Chen RJ, Wang SS, Lin FY, Chen YS. Extracorporeal membrane oxygenation support for adult postcardiotomy cardiogenic shock. Ann Thorac Surg 2002;73(02):538-545

4 Demondion P, Fournel L, Golmard JL, Niculescu M, Pavie A, Leprince P. Predictors of 30-day mortality and outcome in cases of myocardial infarction with cardiogenic shock treated by extracorporeal life support. Eur J Cardiothorac Surg 2014;45(01):47-54

5 Beurtheret S, Mastroianni C, Pozzi M, et al. Extracorporeal membrane oxygenation for 2009 influenza A (H1N1) acute respiratory distress syndrome: single-centre experience with 1-year followup. Eur J Cardiothorac Surg 2012;41(03):691-695

6 Misawa Y, Fuse K, Yamaguchi T, Saito T, Konishi H. Mechanical circulatory assist for pulmonary embolism. Perfusion 2000;15(06): 527-529

7 Boue Y, Lavolaine J, Bouzat P, Matraxia S, Chavanon O, Payen JF. Neurologic recovery from profound accidental hypothermia after 5 hours of cardiopulmonary resuscitation. Crit Care Med 2014;42 (02):e167-e170

8 Ahn C, Kim W, Cho Y, Choi KS, Jang BH, Lim TH. Efficacy of extracorporeal cardiopulmonary resuscitation compared to conventional cardiopulmonary resuscitation for adult cardiac arrest patients: a systematic review and meta-analysis. Sci Rep 2016;6:34208

9 Blumenstein J, Leick J, Liebetrau C, et al. Extracorporeal life support in cardiovascular patients with observed refractory inhospital cardiac arrest is associated with favourable short and long-term outcomes: a propensity-matched analysis. Eur Heart J Acute Cardiovasc Care 2016;5(07):13-22
10 Boeken U, Ensminger S, Burckhardt M, et al. Erstellung einer S3-Leitlinie "Einsatz der extrakorporalen Zirkulation (ECLS/ ECMO) bei Herz- und Kreislaufversagen". Zeitschrift für Herz-, Thorax- und Gefäßchirurgie 2016;30:318-324

11 Debaty G, Babaz V, Durand M, et al. Prognostic factors for extracorporeal cardiopulmonary resuscitation recipients following out-of-hospital refractory cardiac arrest. A systematic review and meta-analysis. Resuscitation 2017;112:1-10

12 Aubin H, Petrov G, Dalyanoglu H, et al. A suprainstitutional network for remote extracorporeal life support: a retrospective cohort study. JACC Heart Fail 2016;4(09):698-708

13 Lee SW, Han KS, Park JS, Lee JS, Kim SJ. Prognostic indicators of survival and survival prediction model following extracorporeal cardiopulmonary resuscitation in patients with sudden refractory cardiac arrest. Ann Intensive Care 2017;7(01):87

14 Beckmann A, Benk C, Beyersdorf F, et al; ECLS Working Group. Position article for the use of extracorporeal life support in adult patients. Eur J Cardiothorac Surg 2011;40(03):676-680

15 Feindt P, Benk C, Boeken U, et al. Use of extracorporeal circulation (ECC) outside the cardiac operating room: indications, requirements and recommendations for routine practice. Thorac Cardiovasc Surg 2011;59(02):66-68

16 Tepper S, Masood MF, Baltazar Garcia M, et al. Left ventricular unloading by Impella device versus surgical vent during extracorporeal life support. Ann Thorac Surg 2017;104(03): 861-867

17 Sy E, Sklar MC, Lequier L, Fan E, Kanji HD. Anticoagulation practices and the prevalence of major bleeding, thromboembolic events, and mortality in venoarterial extracorporeal membrane oxygenation: a systematic review and meta-analysis. J Crit Care 2017;39:87-96 